\title{
Research on Quality Evaluation of Operational Requirement Scheme of Equipment Based on War Experimentation Demonstration
}

\author{
Shigui Wang ${ }^{1, \text { a }}$, Jikuo $\mathrm{Li}^{1, \mathrm{~b}}$, Mian Fu ${ }^{1, \mathrm{c}}$ and Yi Fang ${ }^{2, \mathrm{~d}}$ \\ ${ }^{1}$ Artillery Department, Army Officer Academy, PLA, Hefei, 230031, China \\ ${ }^{2}$ Basic Research Department, Army Officer Academy, PLA, Hefei, 230031, China \\ a,bemail: shigui_wang@126.com, ${ }^{c, d}$ email: fm15395112646@126.com
}

\begin{abstract}
Keywords: Operational Requirement, Scheme, Equipment, War Experimentation, Quality Evaluation
\end{abstract}

\begin{abstract}
This paper puts forward a new method named war experimentation demonstration to evaluate the quality of operational requirement scheme of equipment. Based on defining the correlative concept of operational requirement scheme of equipment, its quality evaluation, and war experimentation demonstration, this research studies and designs the architecture, the function and the flow of war experimentation demonstration for evaluating the quality of operational requirement scheme of equipment. The architecture describes a framework to solve the question. The function includes the management of operational requirement scheme of equipment, the management of the campaign idea, the management of the battlefield situation, the management of war data, the management of war knowledge, the management of war experimentation member, the management of evaluation member, the management of reasoning rule, the running of war experimentation, the evaluation of war experimentation, and the management of evaluation gist. The flow includes nine steps. This establishes the foundation for deepening the quality evaluation of operational requirement demonstration of equipment, and especially the quality evaluation of operational requirement scheme of equipment.
\end{abstract}

\section{Introduction}

An operational requirement scheme of equipment is the final production of an operational requirement demonstration of equipment. Whether the operational requirement demonstration of equipment is successful or not is decided by its quality height. So it can verify and validate the scientific degree of the operational requirement demonstration of equipment by evaluating the quality of the operational requirement scheme of equipment. How to do we evaluate the quality of the operational requirement scheme of equipment? Is one road unblocked or not? We can know easily by passing it through. Similarly we can also know easily the quality of operational requirement scheme of equipment by practicing and demonstrating the scheme. So this paper puts forward adopting war experimentation demonstration to verify and validate the quality of operational requirement scheme of equipment.

\section{Correlative Concept}

Operational Requirement Scheme of Equipment ${ }^{[1]}$.An operational requirement scheme of equipment is the countermeasure, measure and approach taken for solving an operational requirement question of equipment to achieve given object. It is the scheme that is used to solve the question of equipment development, building and programming, according to the task that the army need to burden. The scheme is the standardization description for the result of an operational requirement demonstration of equipment. It is the basic gist to establish metaphase or long-term programming for equipment development, and to develop the demonstration for equipment development. An operational requirement scheme of equipment should accurately describe what the user wants to do and wants to achieve, and make the manufacturer to understand the requirement of the user. According to the production course of operational requirement of equipment, an 
operational requirement scheme of equipment usually includes the applicability explanation, the campaign idea summary, the task analysis, war capability requirement, the realization approach conceit, etc.

Quality Evaluation of Operational Requirement Scheme of Equipment. A quality evaluation of operational requirement scheme of equipment is an action course to evaluate the quality of operational requirement scheme of equipment. The estimator needs to judge whether the quality is coincident or not between the scheme and the factual need. The quality of operational requirement scheme of equipment can decide the development of equipment. So we should attach importance to the quality of operational requirement scheme of equipment so that its quality can be guaranteed from the beginning.

War Experimentation Demonstration ${ }^{[1]}$.War experimentation demonstration is to use the technique of the computer and the network to implement war simulation or the maneuver of the scheme in the simulation or true environment. This can verify, validate and even perfect the scheme. War experimentation demonstration can evaluate the quality of the scheme from the bottom of war and recognize war rule and war direction rule.

\section{The Architecture of War Experimentation Demonstration for the Quality Evaluation of the Scheme}

We earnestly think about this question and draw the following conclusion. The architecture of war experimentation demonstration for the quality evaluation of the scheme is shown in Figure 1.

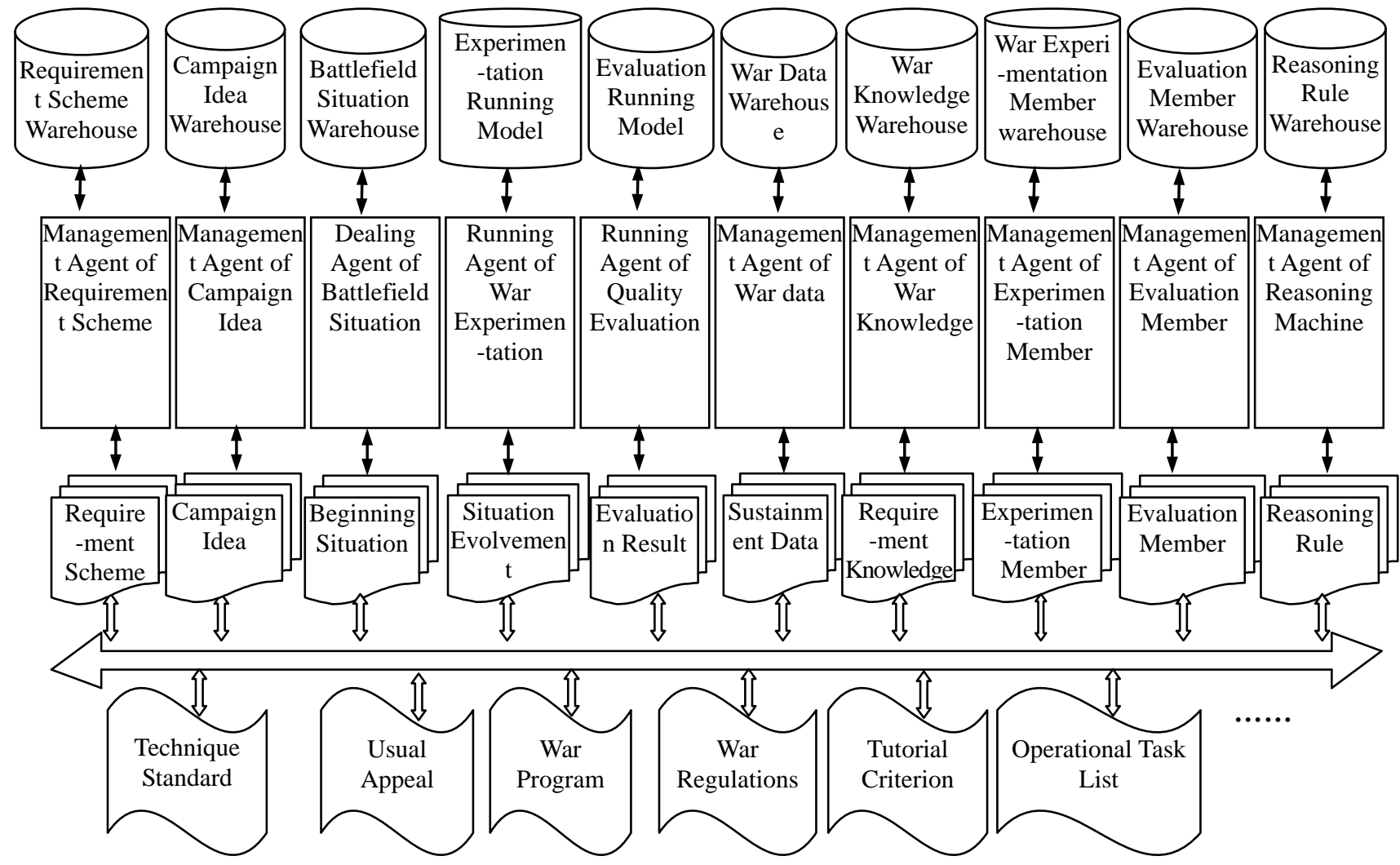

Figure 1: the Architecture of War Experimentation Demonstration for the Quality Evaluation of the Scheme

\section{The Function of War Experimentation Demonstration for the Quality Evaluation of the Scheme}

Its function mainly includes the management of operational requirement scheme of equipment, the management of the campaign idea, the management of the battlefield situation, the management of 
the war data, the management of the war knowledge, the management of the war experimentation member, the management of the evaluation member, the management of the reasoning rule, the running of war experimentation, the evaluation of war experimentation, and the management of the evaluation gist ${ }^{[2][3]}$.

First function is the management of operational requirement scheme of equipment. We need to create the management agent of operational requirement scheme of equipment and the scheme warehouse. The warehouse is used to manage all kinds of schemes. The management agent can not only store a new scheme into the warehouse but also read, amend or delete the special scheme from the warehouse.

Second function is the management of the campaign idea. We need to create the management agent of the campaign idea and the campaign idea warehouse. The campaign idea comes from operational requirement scheme of equipment. The campaign idea warehouse is used to manage all kinds of campaign ideas. The management agent of the campaign idea can not only store a new campaign idea into the warehouse but also read, amend or delete the special campaign idea from the warehouse.

Third function is the management of the battlefield situation. We need to create the management agent of the battlefield situation and the battlefield situation warehouse. The battlefield situation warehouse is used to manage all kinds of battlefield situations. The management agent of the battlefield situation can not only store a new battlefield situation into the warehouse but also read, amend or delete the special battlefield situation from the warehouse.

Fourth function is the management of the war data. We need to create the management agent of the war data and the war data warehouse. The war data warehouse is used to manage all kinds of war data. The management agent of the war data can not only store new war data into the warehouse but also read, amend or delete the special war data from the warehouse.

Fifth function is the management of the war knowledge. We need to create the management agent of the war knowledge and the war knowledge warehouse. The war knowledge warehouse is used to manage all kinds of war knowledge. The management agent of the war knowledge can not only store new war knowledge into the warehouse but also read, amend or delete the special war knowledge from the warehouse.

Sixth function is the management of war experimentation member. We need to create the management agent of war experimentation member and the war experimentation member warehouse. The war experimentation member warehouse is used to manage all kinds of war experimentation members, like unit agent. The management agent of the war experimentation member can not only store a new war experimentation member into the warehouse but also read, amend or delete the special war experimentation member from the warehouse.

Seventh function is the management of the evaluation member. We need to create the management agent of the evaluation member and the evaluation member warehouse. The evaluation member warehouse is used to manage all kinds of evaluation members, like tactic task evaluation member. The management agent of the evaluation member can not only store a new evaluation member into the warehouse but also read, amend or delete the special evaluation member from the warehouse.

Eighth function is the management of reasoning rule. We need to create the management agent of reasoning rule and the reasoning rule warehouse. The reasoning rule warehouse is used to manage all kinds of reasoning rules, like the mapping rule between the task and the capability. The management agent of reasoning rule can not only store a new reasoning rule into the warehouse but also read, amend or delete the special reasoning rule from the warehouse.

Ninth function is the running of war experimentation. We need to create the running agent of war experimentation and the running model warehouse of war experimentation. The running model warehouse is used to manage all kinds of running models. The management agent of the running model can not only store a new model into the warehouse but also read, amend or delete the special model from the warehouse. 
Tenth function is the evaluation of war experimentation. We need to create the evaluation agent of war experimentation and the evaluation model warehouse of war experimentation. The evaluation members can draw the evaluation graphics by using the model and the data. Then they can find the orderliness from the graphics and draw an evaluation conclusion.

The final function is the management of evaluation gist. The evaluation gist mainly includes Usual Appeal of Operational Requirement Demonstration of Equipment, Task List, Description of Operational Requirement Demonstration of Equipment, War Program, War Regulations, and Correlative Tutorial. War experimentation demonstration needs to use the gist ${ }^{[4][5][6]}$.

\section{The Flow of War Experimentation Demonstration for the Quality Evaluation of the Scheme}

A general flow of war experimentation demonstration for the quality evaluation of the scheme is given like Figure 2. Suppose the total war stages are equal to $\mathrm{N}$.

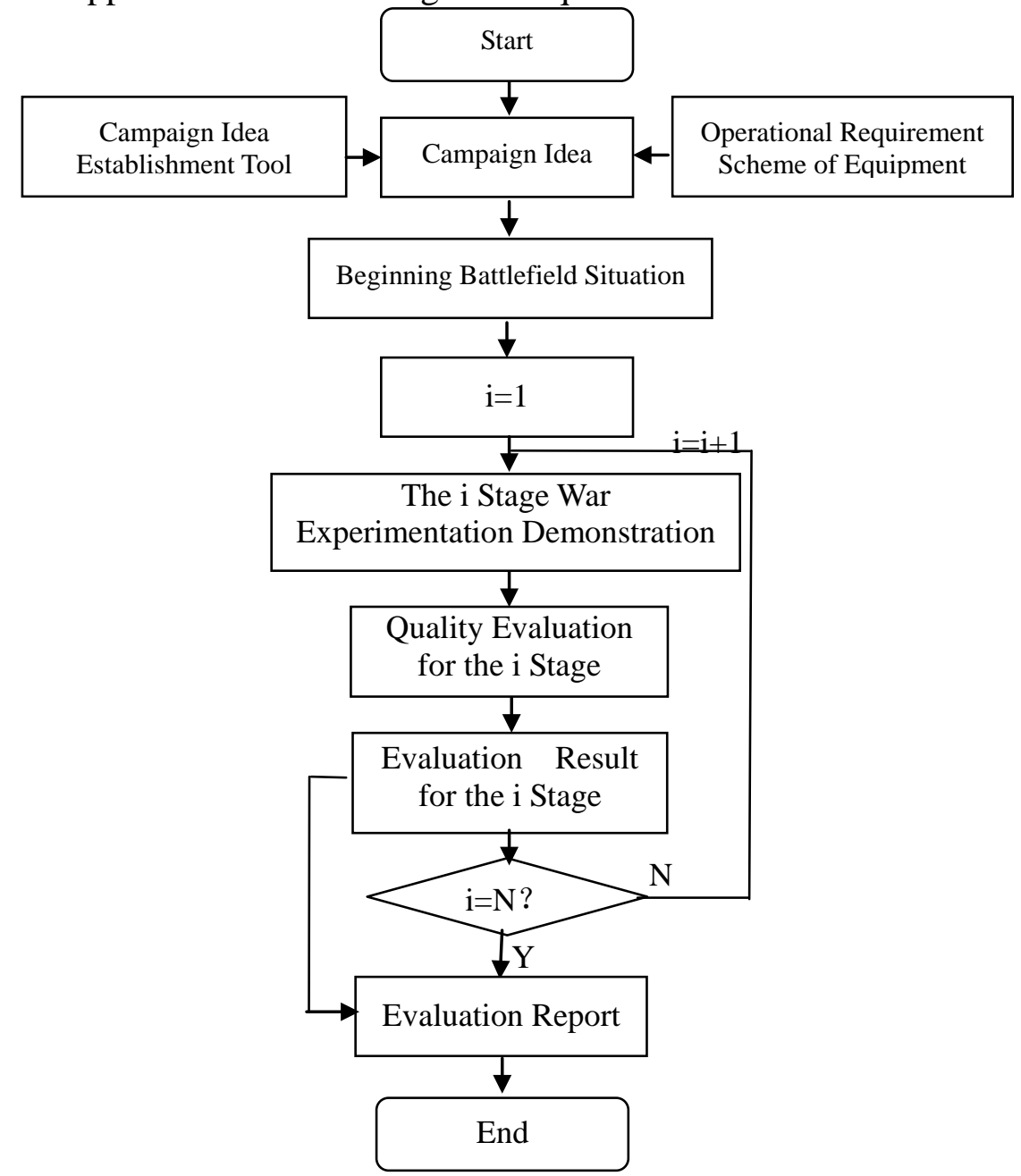

Figure 2 A flow of war experimentation demonstration for the quality evaluation of the scheme

Step 1: Based on the operational requirement scheme of equipment, establish the campaign idea according to the normative format. Switch to Step 2.

Step 2: Come into being the beginning battlefield situation. Switch to Step 3.

Step 3: Suppose the following: the variable i is equal to 1. Switch to Step 4.

Step 4: According to the plan, carry out war experimentation for the i stage under the simulation or true environment. Switch to Step 5.

Step 5: Evaluate the quality of war experimentation demonstration for the i stage by using the evaluation tool. Switch to Step 6.

Step 6: Draw a conclusion for the i stage. Switch to Step 7.

Step 7: Judge whether i is over or not. If not, switch to Step 8, or switch to Step 9.

Step 8: I is equal to $\mathrm{i}+1$. Switch to Step 4. 
Step 9: Form the evaluation report, and hand it in.

\section{Summary}

We studied the quality evaluation of operational requirement scheme of equipment by using war experimentation demonstration and designed the architecture, the function and the flow of war experimentation demonstration for the quality evaluation of the scheme. We hope that this paper can establish the foundation for deepening the quality evaluation of operational requirement demonstration of equipment, and especially the quality evaluation of operational requirement scheme of equipment.

\section{Acknowledgement}

In this paper, the research was sponsored by the Nature Science Foundation of China (Project No. 71371187).

\section{References}

[1] WANG Shigui, WANG Shumin, FU Mian, Evaluation Method for Equipment Operational Requirement Demonstration [J], Journal of Equipment Academy. 2014, 25(3):23-26.

[2] WANG Shigui, ZHOU Fengping, ZHANG Qingjie, Quality Evaluation Method of Operational Task List for Demonstration of Operational Equipment Requirement [J], Journal of Equipment Academy. 2015, 26(2):18-22.

[3] Li Jikuo, FU Mian, WANG shigui, Study on Course Quality Evaluation Data System of Operational Requirement Demonstration of Equipment [J], Journal of Equipment Academy. 2015, 26(6):22-27.

[4] CHEN Juan, WANG Shumin, WANG Shigui, Quality Evaluation Method of Operational Requirement Plan on Unmanned Aerial Vehicles Based on Compound Intelligent Model[J], Journal of Equipment Academy. 2015, 26(6):27-32.

[5] WANG Shigui, QIU Chaofan, ZHAO Lin, Quality Evaluation Method of Capability Requirement among Operational Requirement Demonstration of Equipment [J], Journal of Army Officer Academy. 2015, 35(4):29-41.

[6] WANG Shigui, MI Liang, FU Mian, Quality Evaluation Index and Model of Operational Capability System of System Based on Capability View [J], Journal of Army Officer Academy. 2016, 36(2):50-52. 